\title{
6 Climbing
}

\section{New sport on the block}

\section{Wolfram Manzenreiter}

Climbing has come a long way since its inception by Victorian mountaineers and local guides in the European Alps. For most of its history, the sheer idea of competitions and indoor climbing was a sacrilege to many that celebrated mountain climbing as a "brotherhood of the rope" and life-transcending quest in the wilderness. Risk-reducing devices, grading standards, and artificial climbing walls in urban gyms facilitated the transformation into a sport of its own and the emergence of a colorful subculture with its own media, brands, and celebrities.

The Japan Mountaineering and Sport Climbing Association (JMSCA, until 2017 just JMA) is in charge of sport climbing, including the execution of rules, judging, licensing, and contests. About 550 climbing gyms are in operation in Japan, about 100 in Tokyo alone. User fees are moderate, and the sport is easy to learn and fascinating to watch. Climbing requires physical strength and agility, as well as mental strength and imagination in how to solve a problem on the climbing wall. Top athletes can challenge problems side-by-side with children or seniors.

International tournaments have been a vital part of sport climbing since the 1990s. The International Federation of Sport Climbing (IFSC) oversees championships and cup tournaments in three distinctive categories for men and women. In lead climbing, athletes climb up a vertical route as high as possible. Speed climbing is basically a head-to-head race along a fixed route on a ten or 15-meter wall; in bouldering, climbers tackle as many technically challenging routes as possible on a four-meter wall. At Tokyo 2020, 20 men and women compete in all disciplines. Aggregated results determine the ultimate ranks. Qualifiers are taking place at three tournaments in the lead-up to the Games; two slots are guaranteed to Japan, and two are bestowed on invitees.

Climbing's Olympic debut in 2020 is no surprise when the host's ambitions for gold are taken into consideration. In the past four World Cup seasons, Japan won the team competition. As of June 2019, 15 of the world's top 50 male lead climbers are Japanese (and nine among women); in bouldering, five of the top ten male climbers are Japanese (women: three). Veteran world champions are Narasaki Tomoa and Noguchi Akiyo, and at the 2018 Youth Olympics in Buenos Aires that introduced the combined event, gold and silver went to Japan's Dohi Keita and Tanaka Shuta. 